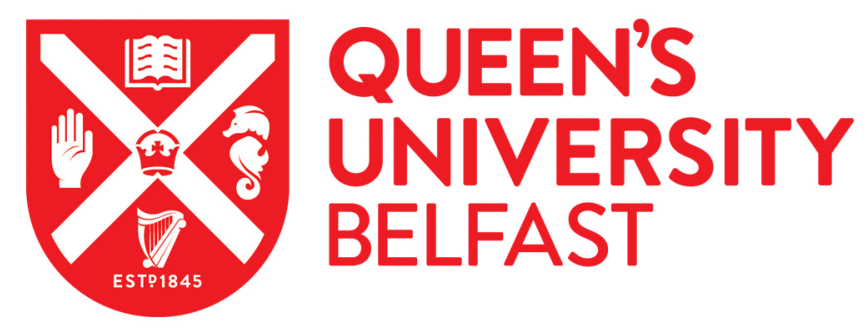

\title{
The macroeconomic impact of non-communicable diseases in China and India: Estimates, projections, and comparisons
}

\author{
Bloom, D. E., Cafiero-Fonseca, E. T., McGovern, M. E., Prettner, K., Stanciole, A., Weiss, J., Bakkila, S., \& \\ Rosenberg, L. (2014). The macroeconomic impact of non-communicable diseases in China and India: \\ Estimates, projections, and comparisons. The Journal of the Economics of Ageing, 4, 100-111. \\ https://doi.org/10.1016/j.jeoa.2014.08.003
}

Published in:

The Journal of the Economics of Ageing

Document Version:

Early version, also known as pre-print

Queen's University Belfast - Research Portal:

Link to publication record in Queen's University Belfast Research Portal

Publisher rights

(c) 2014 The Author(s)

\section{General rights}

Copyright for the publications made accessible via the Queen's University Belfast Research Portal is retained by the author(s) and / or other copyright owners and it is a condition of accessing these publications that users recognise and abide by the legal requirements associated with these rights.

Take down policy

The Research Portal is Queen's institutional repository that provides access to Queen's research output. Every effort has been made to ensure that content in the Research Portal does not infringe any person's rights, or applicable UK laws. If you discover content in the Research Portal that you believe breaches copyright or violates any law, please contact openaccess@qub.ac.uk. 
NBER WORKING PAPER SERIES

THE ECONOMIC IMPACT OF NON-COMMUNICABLE DISEASE IN CHINA AND INDIA: ESTIMATES, PROJECTIONS, AND COMPARISONS

\author{
David E. Bloom \\ Elizabeth T. Cafiero \\ Mark E. McGovern \\ Klaus Prettner \\ Anderson Stanciole \\ Jonathan Weiss \\ Samuel Bakkila \\ Larry Rosenberg \\ Working Paper 19335 \\ http://www.nber.org/papers/w19335
NATIONAL BUREAU OF ECONOMIC RESEARCH
1050 Massachusetts Avenue
Cambridge, MA 02138
August 2013

Manuscript prepared for presentation at "The Economics of Population Aging in China and India", a conference sponsored jointly by the Program on the Global Demography of Aging, the South Asia Initiative, the Asia Center, the Harvard-Yenching Institute, the Harvard China Fund, and the Weatherhead Center for International Affairs (all at Harvard University), and the Walter H. Shorenstein Asia-Pacific Research Center (at Stanford University). We would like to thank Andrew Mason and the participants of the Economics of Population Aging in China and India conference for valuable comments and suggestions. Lauren Gurfein and Benjamin Osher provided helpful assistance. Funding source: This study was funded in part by the Program on the Global Demography of Aging, which receives funding from the National Institute on Aging, Grant No. 1 P30 AG024409-06. The views expressed herein are those of the authors and do not necessarily reflect the views of the National Bureau of Economic Research.

NBER working papers are circulated for discussion and comment purposes. They have not been peerreviewed or been subject to the review by the NBER Board of Directors that accompanies official NBER publications.

(C) 2013 by David E. Bloom, Elizabeth T. Cafiero, Mark E. McGovern, Klaus Prettner, Anderson Stanciole, Jonathan Weiss, Samuel Bakkila, and Larry Rosenberg. All rights reserved. Short sections of text, not to exceed two paragraphs, may be quoted without explicit permission provided that full credit, including ( $)$ notice, is given to the source. 
The Economic Impact of Non-Communicable Disease in China and India: Estimates, Projections, and Comparisons

David E. Bloom, Elizabeth T. Cafiero, Mark E. McGovern, Klaus Prettner, Anderson Stanciole, Jonathan Weiss, Samuel Bakkila, and Larry Rosenberg

NBER Working Paper No. 19335

August 2013

JEL No. E13,I15,O40

\begin{abstract}
This paper provides estimates of the economic impact of non-communicable diseases (NCDs) in China and India for the period 2012-2030. Our estimates are derived using WHO's EPIC model of economic growth, which focuses on the negative effects of NCDs on labor supply and capital accumulation. We present results for the five main NCDs (cardiovascular disease, cancer, chronic respiratory disease, diabetes, and mental health). Our undiscounted estimates indicate that the cost of the five main NCDs will total USD 27.8 trillion for China and USD 6.2 trillion for India (in 2010 USD). For both countries, the most costly domains are cardiovascular disease and mental health, followed by respiratory disease. Our analyses also reveal that the costs are much larger in China than in India mainly because of China's higher income and older population. Rough calculations also indicate that WHO's Best Buys for addressing the challenge of NCDs are highly cost-beneficial.
\end{abstract}

David E. Bloom

Harvard School of Public Health

Department of Global Health and Population

665 Huntington Ave.

Boston, MA 02115

and NBER

dbloom@hsph.harvard.edu

Elizabeth T. Cafiero

Harvard School of Public Health

Department of Global Health and Population

665 Huntington Avenue

Building 1, Suite 1202

Boston, MA 02115

ecafiero@hsph.harvard.edu

Mark E. McGovern

Harvard Center for Population

and Development Studies

9 Bow Street

Cambridge, Massachusetts 02138

mcgovern@hsph.harvard.edu

Klaus Prettner

Department of Economics

University of Göttingen

Room 2.138 Platz der Goettinger

Sieben 3 D-37073

Goettingen Germany

Klaus.prettner@wiwi.uni-goettingen.de
Anderson Stanciole

The Bill and Melinda Gates Foundation

500 5th Ave N

Seattle, WA 98109

Anderson.Stanciole@gatesfoundation.org

Jonathan Weiss

London School of Hygiene and Tropical Medicine

Keppel Street, London WC1E 7HT

United Kingdom

and UNICEF Supply Division, Copenhagen, Denmark

jonathan.weiss@1shtm.ac.uk

Samuel Bakkila

Department of Global Health and Population

Harvard School of Public Health

665 Huntington Avenue

Building I 12th Floor, Suite 1202

Boston, Massachusetts 02115

sbakkila@gmail.com

Larry Rosenberg

Department of Global Health and Population

Harvard School of Public Health

665 Huntington Avenue

Building I 12th Floor, Suite 1202

Boston, Massachusetts 02115

larry_rosenberg@harvard.edu 


\section{Introduction}

Previous research has documented the impact of non-communicable diseases (NCDs) worldwide, in terms of avoidable deaths (Marrero, Bloom, \& Adashi, 2012), disability (Murray, et al., 2012a, 2012b; Salomon, et al., 2012), and economic impact (Abegunde, Mathers, Adam, Ortegon, \& Strong, 2007; Bloom et al., 2011b, 2011c). Studies have highlighted the potential increase in chronic disease in developing and emerging nations and the overall impact on population health that this could have (Kearney et al., 2005). In fact, NCDs are responsible for 65.5 percent of all mortality (Lozano et al., 2012), and account for 54 percent of healthy life years lost, as measured by Disability-Adjusted Life Years (DALYs) (Murray et al., 2012b). Differentials in health-related behaviors and outcomes represent an important component of disparities between the well-being of populations, both across countries and over time (Becker, Philipson, \& Soares, 2005). A comparison of India and China offers a good example. The economies of both countries have undergone significant changes in terms of demographic and economic structure (Bloom et al., 2010); however, recent estimates suggest that health and disability may represent significant impediments to further growth, but with different outcomes for the two countries.

The global burden of non-communicable diseases is expected to increase as a result of two related demographic phenomena (Bloom, et al., 2011a, 2011b), first the rise in global population, and second the growth of the older population. This is particularly the case for certain emerging nations, such as China and India. Currently 5.3 percent of India's population and 8.6 percent of China's is aged 65 or older; however, this will increase to 10.2 percent and 21 percent, respectively, by 2035 (Wolf et al., 2011). This has important implications for the burden of disease because this age group is the most affected by illness (Bloom et al., 2011b; Dey et al., 2012; Williams \& Krakauer, 2011; National Sample Survey Organisation, 2006). These trends have particularly important implications for emerging nations, which rely on rapid economic transformation to reduce poverty and improve population welfare.

Disease burden can impact economic growth through a number of different pathways. For example, poor health is associated with early retirement (Dwyer \& Mitchell, 1999), negative expectations regarding employment (McGarry, 2004), and reduced productivity (Lopez- 
Casasnovas, Rivera, \& Currais, 2005). These factors may contribute to lowering labor supply and increasing the ratio of dependents to workers.

By increasing public health expenditures to treat NCDs and reducing the amount of household taxable income by pushing ill people out of the workforce, NCDs may reduce the net availability of government resources. As a result, this limited fiscal capacity could compel governments to increase tax rates to meet rising health expenditures, which in turn would depress aggregate demand, further limiting the growth potential of the economy and reducing the public sector's ability to invest in strategic areas. Increased health expenditures would impede the accumulation of physical and human capital (i.e., the portion that arises from better education). In addition, the types of conditions that affect the health of aging populations may require an ever-growing share of resources, thus reducing a government's ability to target poverty reduction or improvements in education.

Existing empirical research has established a strong relationship between economic growth and health, including in China and India (Bloom et al., 2010), reflecting causality running from health to economic growth (Bloom, Canning, \& Sevilla, 2004 \& Bloom, Canning, \& Fink, in press), as well as from the longer-understood effect of economic growth on improved health. One way of estimating the magnitude of the impact of health on economic growth is to construct a macroeconomic model that incorporates health alongside the factors of production. Growth models have a long history in economics, dating back to Solow (1956), who described the process of economic growth as a function of the aggregates of capital and labor. In this paper we adopt the approach in Abegunde and Stanciole (2006), and Bloom et al. (2011b), and allow for an effect of health on national income in two respects. First, NCDs cause the diversion of savings from capital investment into non-productive health care, and second, NCD mortality results in the reduction of the stock of available labor supply.

We present and compare results associated with the burden of disease using this EPIC model from China and India over the time period 2012-2030. We assess the economic impact of four types of NCDs (cardiovascular disease, cancer, chronic respiratory disease, and diabetes), and also include estimates of the effect of mental health. We describe the relative contribution of each to the total and identify the most important of these in terms of overall magnitude. These results allow us to assess the potential impact of NCDs on each economy over the next 18 years. 
The rest of this paper is structured as follows. Section 2 supplies background on the nature and magnitude of NCDs and their risk factors in general as well as in China and India specifically. Section 3 describes the model and data used in the analysis, specifically WHO's EPIC model. Section 4 presents results from China and India, Section 5 discusses the results, and Section 6 provides conclusions and offers suggestions for further research.

\section{Background on NCDs, their prevalence in China and India, and relevant policy implications}

The transition from infectious disease to NCDs as the dominant cause of mortality is usually regarded as a result of successful infectious disease control and greater longevity. However, the first of these claims cannot yet be made for India. As shown in Figure 1, the burden of infectious disease remains high in India, with communicable, maternal, perinatal, and nutritional conditions accounting for 37 percent of all mortality, compared with just 7 percent in China. While China has made good progress with regard to successful infectious disease control, India continues to face a double burden of disease.

\section{Figure 1. Proportion of mortality due to NCDs and other causes in China and India}
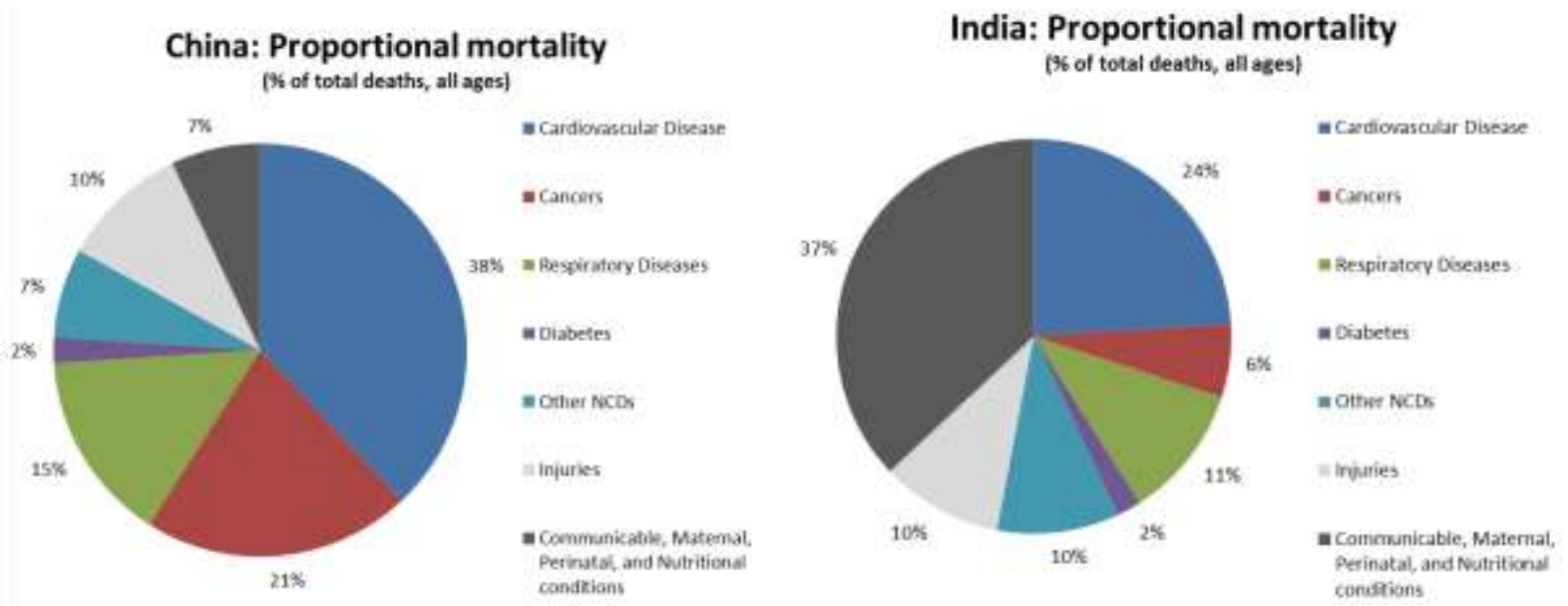

Source: World Health Organization, 2011c

Figure 2 casts some doubt on the strength of the second claim - that greater longevity accounts in part for the new dominance of NCDs as a cause of death - by showing that both China and India experience a substantial burden of premature NCD deaths. Around 60 percent of NCD 
deaths in India and 35 percent in China involve people under the age of 70, in contrast to fewer than 30 percent in much of Western Europe.

\section{Figure 2. Percentage of all NCD deaths occurring under age of 70: Male (left) and Female (right) ${ }^{\mathrm{a}}$}
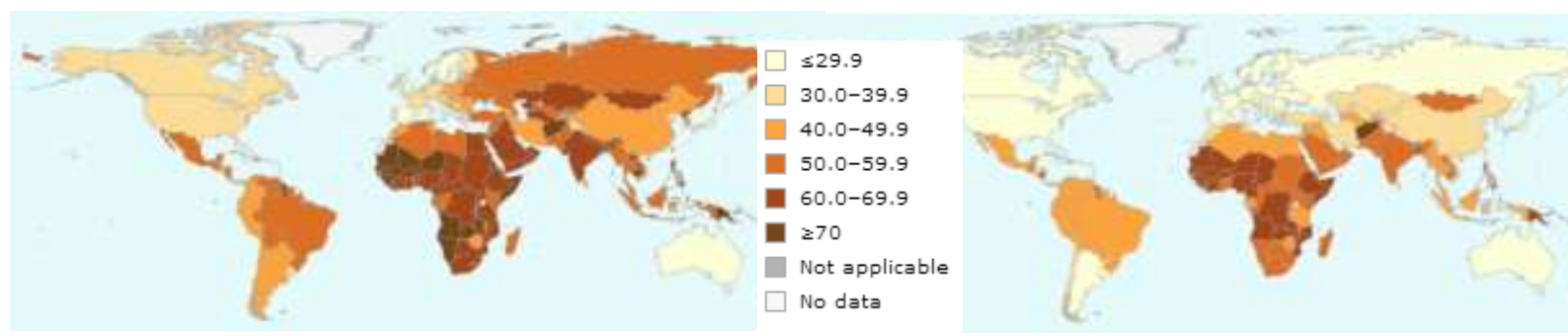

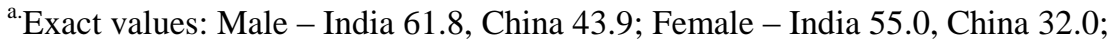

Source: World Health Organization, 2011d.

The development and progression of NCDs is determined by both modifiable and nonmodifiable risk factors. Non-modifiable risk factors include age, sex, and genetic make-up. Although these risk factors cannot be the primary targets of interventions, they are important to consider as they influence the overall burden of disease. Nearly all NCDs increase in prevalence with age (Dey et al., 2012; Williams \& Krakauer, 2011; Zhao, 2013). Due to rapid population aging alone, both China and India will be at increased risk for non-communicable diseases if other risk factors remain reasonably constant.

However, population aging is not the only risk factor that is driving China and India toward an increased burden of NCDs and NCD-related premature mortality. The prevalence of modifiable NCD risk factors, such as tobacco use, harmful alcohol use, poor diet, and sedentary lifestyles has risen steadily over the past 30 years in both countries. These behavioral trends are related to much larger changes in society: increased income, urbanization, and the transition to occupations requiring less physical activity. In the context of China and India, air pollution - both indoor and outdoor - is also an important risk factor due to its role in cancer, chronic lung disease, and cardiovascular disease (Institute for Health Metrics and Evaluation, 2013a, 2013b).

See Table 1 for a comparison of major NCD risk factors. Overall, India fares better than China in terms of modifiable NCD risk factors, with a lower prevalence of risk behaviors such as smoking 
and physical inactivity as well as a lower prevalence of biomarkers for disease such as raised blood pressure and raised cholesterol.

Table 1. Percentage of population with specific NCD risk factors in India and China

\begin{tabular}{c|ccc|ccc}
\hline \multirow{2}{*}{ Risk factors } & \multicolumn{3}{c|}{ India } & \multicolumn{3}{c}{ China } \\
\cline { 2 - 7 } & Men & Women & Total & Men & Women & Total \\
\hline \hline Daily tobacco smoking & 25.1 & 2.0 & 13.9 & 49.3 & 2.1 & 26.3 \\
\hline Overweight (BMI $\left.\geq 25 \mathrm{~kg} / \mathrm{m}^{2}\right)$ & 9.9 & 12.2 & 11.0 & 25.5 & 25.4 & 25.4 \\
\hline Obese (BMI $\left.\geq 30 \mathrm{~kg} / \mathrm{m}^{2}\right)$ & 1.3 & 2.4 & 1.9 & 4.7 & 6.7 & 5.7 \\
\hline Physical inactivity & 10.8 & 17.3 & 14.0 & 29.3 & 32.0 & 30.6 \\
\hline Raised cholesterol & 25.8 & 28.3 & 27.1 & 31.8 & 35.3 & 33.5 \\
\hline Raised blood glucose & 10.0 & 10.0 & 10.0 & 9.5 & 9.3 & 9.4 \\
\hline Harmful use of alcohol & 3.5 & 0.4 & 2.0 & 6.9 & 0.2 & 3.8 \\
\hline Raised blood pressure & 33.2 & 31.7 & 32.5 & 40.1 & 36.2 & 38.2
\end{tabular}

Source: World Health Organization, 2011a, 2011c

Daily tobacco smoking is a major risk factor for which both China and India can improve. China is the world's largest producer and consumer of tobacco. Liu et al. (1998) note that cigarette smoking among Chinese men rose rapidly in the period 1952-1996 and has since stabilized. However, since there is a lag of several decades between the initiation of smoking and smokingrelated morbidity and mortality, the full health implications of the previous increases in smoking have not yet been observed. Roughly 10 percent of the world's smokers are in India, which is the second largest group of smokers in the world, after only China. In India, beedi smoking (also spelled bidi or biri) is common, and accounts for about half of Indian tobacco consumption. Beedies are filterless Indian cigarettes that consist of tobacco rolled in a tendu or temburni leaf and may be flavored. While beedies are seen as a low-cost alternative to cigarettes, they may be more harmful than conventional cigarettes, because they deliver more nicotine, carbon monoxide, and tar (Centers for Disease Control and Prevention, 2013; Ministry of Health and Family Welfare, 2008). Taxes on cigarettes are low and typically do not apply to beedies due to the fact that their sale is poorly regulated (John et al., 2010). Indians consume tobacco in other forms, as well, including gutka and pan masala (types of chewing tobacco). Data from the third 
wave of India's National Family Healthy Survey show that among individuals aged 15-49, 57 percent of men and 11 percent of women use tobacco in some form (International Institute for Population Sciences, 2007; Parasuraman et al., 2009).

The prevalence of overweight (see Figure 3) is higher in China than India and continues to rise in both countries. Asians are at risk for diabetes at lower BMIs than Caucasians. Measures of central adiposity, such as waist/hip ratio, are therefore preferred to BMI for South Asia (Dudeja et al., 2001), but these data are not available on a national level.

Figure 3. Prevalence of overweight, ages 20+, age-standardized: Male (left) and Female (right)

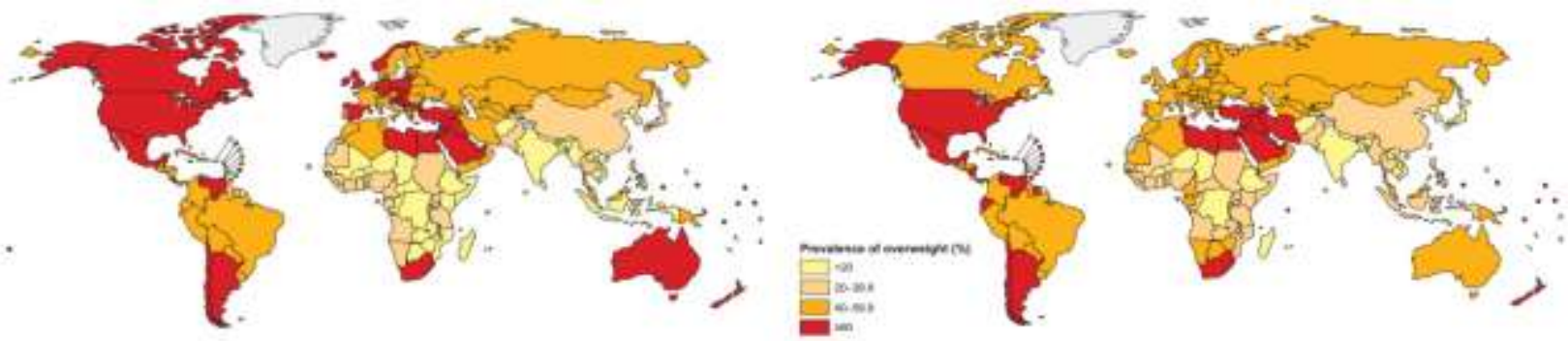

Source: World Health Organization, 2011b

Though a thorough review of the nutrition transition in China and India is beyond the scope of this paper, it is important to note that changes in diet can have an independent effect on NCD risk, in addition to changing BMI. Popkin et al. (2001) note that in both China and India, dietary changes have heightened NCD risk, with an increase in meat consumption and edible oils in China, and increased dairy and added sugar in India.

Having reviewed the major risk factors, we can now consider different NCDs as causes of mortality. As shown in Figure 1, NCDs account for a greater proportion of overall mortality in China than India: 83 percent and 53 percent, respectively. Furthermore, absolute NCD mortality is greater in China than it is in India; NCDs caused an estimated 8 million deaths in China in 2008, and 5 million deaths in India (World Health Organization, 2011b). However, it is important to note that this is largely due to differences in age structure. China currently has an older population than India, and age itself is a risk factor for NCDs. As shown in Figure 4, India actually has a slightly higher age-standardized death rate than China for NCDs overall. This is 
due to the greater prevalence of ischemic heart disease in India, as compared with China (see Figure 5).

Figure 4. NCDs: broad causes of mortality, age-standardized rates

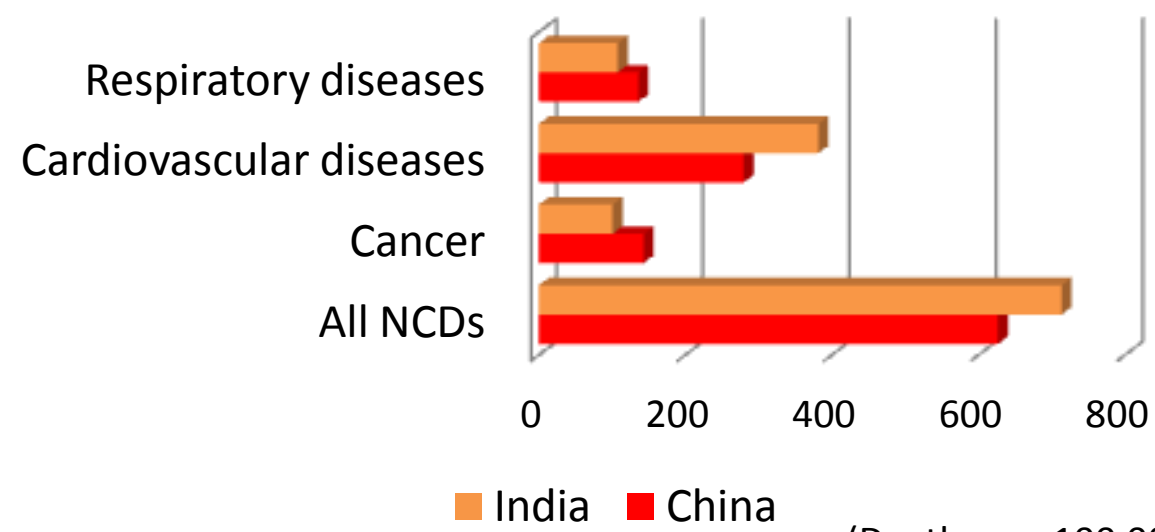

(Deaths per 100,000)

Source: World Health Organization, 2008.

Figure 5 shows specific diseases of interest, either because they are large contributors to overall NCD mortality, or because prevalence was markedly different in China and India. The overall age-standardized mortality attributable to cardiovascular disease is moderately higher for India than China, but there is variation within this category, with India having much higher mortality from ischemic heart disease - commonly called a "heart attack" - and China having higher mortality for cerebrovascular disease, or stroke. 


\section{Figure 5. NCD-specific causes of mortality, age-standardized rates}

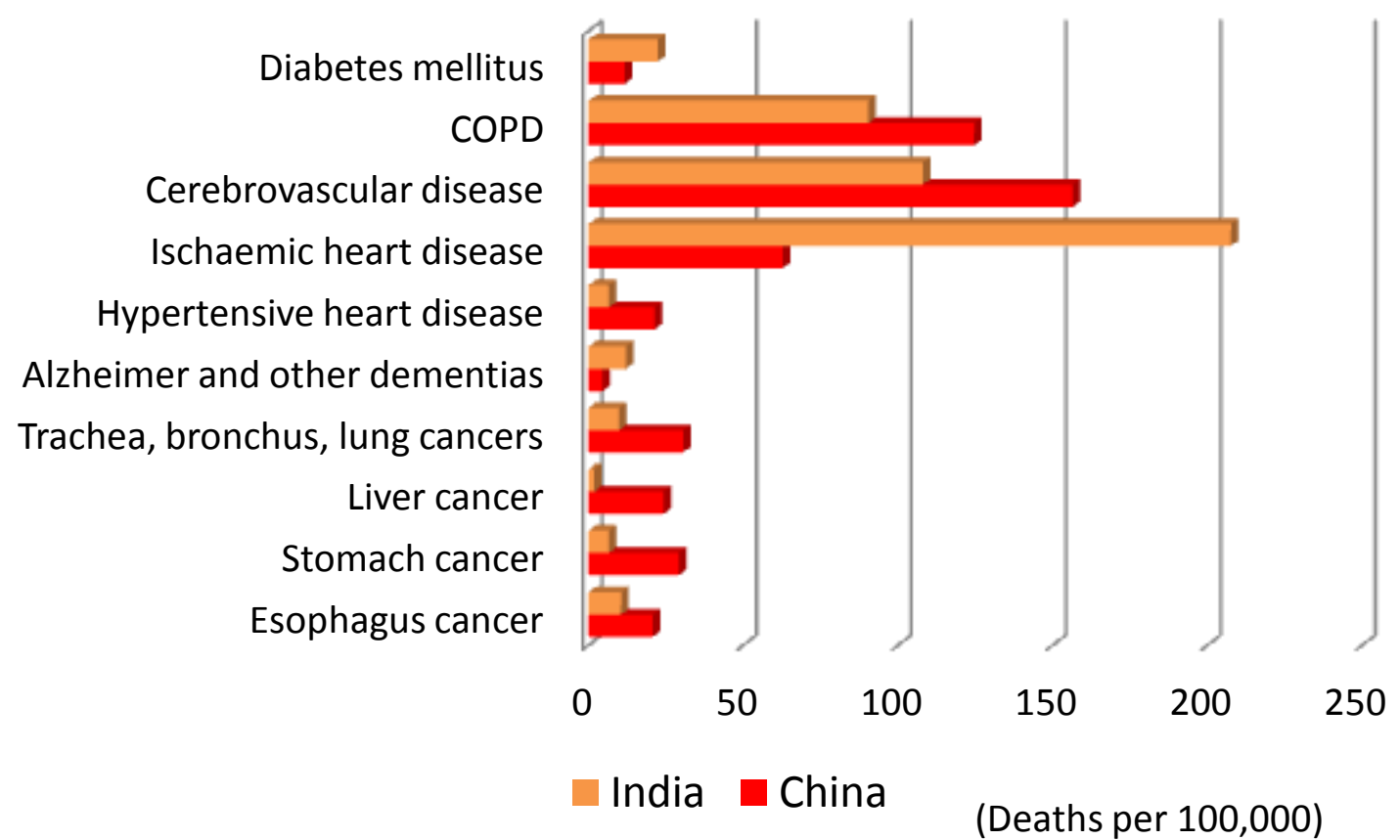

Source: World Health Organization, 2008.

China has substantially higher age-standardized mortality from cancer overall, with particularly elevated rates of death from cancers of the esophagus, stomach, colon and rectum, liver, and trachea, bronchus, and lung. These outcomes are associated with smoking, outdoor air pollution, a diet low in fruits and high in sodium (stomach cancer), and low physical activity (colon and rectum cancers). India fares worse than China when it comes to mortality due to female cancers. The age-standardized mortality rates from breast and cervical cancer are approximately three times higher in India than in China (Ferlay et al., 2013). ${ }^{1}$

In light of the large and growing health burdens of NCDs in China and India, we review some NCD-related policies and their potential health implications. Table 2 shows some of the WHO "best buys" - a set of interventions designed to reduce NCD mortality and morbidity, and identified as being highly cost-effective and feasible to implement given the constraints of many low- and middle-income country health systems (Bloom et al., 2011b, 2011c; World Health Organization, 2011b). The first three sets of interventions address risk factors and the final two

\footnotetext{
${ }^{1}$ Age-standardized mortality rates for breast cancer and cervical cancer are 5.7 and 4.3 per 100,000 population in China and 11.1 and 15.2 per 100,000 population in India, respectively.
} 
sets focus on the medical management of NCDs. Here we discuss China and India's current policies on tobacco control and cardiovascular disease therapy, since these are the most effective of the identified best buys in terms of preventing avoidable deaths.

\section{Table2: "Best Buy" interventions for reducing NCDs}

\begin{tabular}{|l|l|}
\hline Risk factor/disease & Interventions \\
\hline Tobacco use & $\begin{array}{l}\text { - Tax increases } \\
\text { - Smoke-free indoor workplaces and public places } \\
\text { - Health information and warnings } \\
\text { - Bans on tobacco advertising, promotion and } \\
\text { sponsorship }\end{array}$ \\
\hline Harmful alcohol use & $\begin{array}{l}\text { - Tax increases } \\
\text { - Restricted access to retailed alcohol } \\
\text { - Bans on alcohol advertising }\end{array}$ \\
\hline Unhealthy diet and physical inactivity & $\begin{array}{l}\text { - Reduced salt intake in food } \\
\text { - Replacement of trans fat with polyunsaturated fat } \\
\text { - Public awareness through mass media on diet and } \\
\text { physical activity }\end{array}$ \\
\hline Cardiovascular disease (CVD) and diabetes & $\begin{array}{l}\text { - Counselling and multi-drug therapy for people with } \\
\text { a high risk of developing heart attacks and strokes } \\
\text { (including those with established CVD) }\end{array}$ \\
\hline Cancer & $\begin{array}{l}\text { - Treatment of heart attacks with aspirin } \\
\text { - Hepatitis B immunization to prevent liver cancer } \\
\text { (already scaled up) }\end{array}$ \\
\hline $\begin{array}{l}\text { - Screening and treatment of pre-cancerous lesions } \\
\text { to prevent cervical cancer }\end{array}$ \\
\hline
\end{tabular}

There has been mixed progress on tobacco control in China. Ma et al. (2010) explain that some local governments have implemented smoking bans in public places, such as hospitals, schools, and public transportation, but that compliance remains low. China increased the excise tax on tobacco products in 2009, but Gao, Zheng, and $\mathrm{Hu}$ (2012) find that because the Chinese State Tobacco Monopoly Administration (STMA) determines prices, this tax increase has not raised retail prices or decreased tobacco consumption, as has occurred in many market economies that adopted higher excise taxes on tobacco. Although there is a ban on tobacco advertising on television, radio, and in newspapers, there is not currently a restriction on other sponsorship activities. Tobacco sponsorship and advertising in schools and libraries therefore remains 
strong. ${ }^{2}$ While China's cigarette packages are required to provide a general warning that smoking is harmful for health, these warnings are small and ineffective and do not provide specific information or images about the health risks of smoking. Wan et al. (2012) suggest that conflict of interest, where the STMA is both the tobacco industry and its regulator, prevents effective implementation of tobacco control measures.

There is a similar situation with regard to tobacco control in India. India signed and ratified the global Framework Convention on Tobacco Control, but compliance in terms of smoking bans in public places and restrictions on advertisements remains poor (Goel, Ravindra, Singh, \& Sharma, 2013; John, et al. 2010). There has been some recent progress; for example, in April 2013, the Government of India enacted "The Cigarettes and Other Tobacco Products (Prohibition of Advertisement and Regulation of Trade and Commerce, Production, Supply and Distribution) Act, 2003" (COTPA 2003), which requires all tobacco products to carry pictorial health warnings (Press Information Bureau, 2013). In June 2013, Karnataka became the $26^{\text {th }}$ Indian state to ban the manufacture and sale of tobacco-containing gutka and pan masala (Express News Service, 2013).

Another major policy challenge is improving medical management of chronic conditions. This is also known as secondary prevention (i.e., methods to diagnose and treat existing disease before it causes significant morbidity). A major barrier to secondary prevention is the poor availability of NCD medicines in low- and middle-income countries, including China and India (van Mourik, Cameron, Ewen, \& Laing, 2010; Mendis, 2007). Many times, basic medications such as insulin to manage diabetes, antihypertensive drugs, or aspirin for heart attack fatality reduction, which can hugely impact the course of NCDs, are not available from local pharmacies, or are only available at a prohibitive price. Health systems can fail at many points: surveillance, diagnosis, access to medicines, and patient adherence ( $\mathrm{Gu}$ et al., 2002). China and India have the potential to improve access to NCD medications, with a growing healthcare workforce and a growing pharmaceutical industry. India has recently taken steps to improve access to essential medicines. The Government of India announced that it will implement a price ceiling on all drugs on the national essential medicines list and, as part of its goal to increase public healthcare spending,

\footnotetext{
${ }^{2}$ For more information on tobacco's role in sponsoring schools, see: http://www.bloomberg.com/news/2011-0920/china-endorsing-tobacco-in-schools-adds-to-10-trillion-gdp-cost.html
} 
will provide these drugs for free to government-run hospitals and clinics in a $75 \%-25 \%$ costsharing arrangement with the states (Baja, 2012; Singha, 2012). Following the example of Tamil $\mathrm{Nadu}$, a central procurement agency will be developed, and the government expects generic manufacturers to supply the drugs.

Furthermore, China and India will need to build infrastructure to deal with the aging population. While recent research suggests that China's efforts to expand insurance coverage have reached a substantial proportion of the over-45 age group, further action is needed to fully cover these individuals and protect them from impoverishing out-of-pocket spending (Strauss et al., 2012). Research from India cites low levels of access to insurance for the older population and a great need for building up the capacity to deliver geriatric care across the country (Dey et al., 2012; Evans et al., 2011).

\section{Model and data}

Several modeling approaches have been used to estimate the aggregate economic impact of disease (World Health Organization, 2009). A common methodology is the cost-of-illness or human capital approach, which combines 'direct costs' (medical care, travel costs, etc.) and 'indirect costs' (the value of lost production because of reduced working time) into an overall estimate of economic impact on society, often expressed as a percentage of current GDP. Although the cost-of-illness approach focuses on the societal impact of disease or injury, it provides only a partial picture of the true macroeconomic impact of disease, and fails to consider the contribution of depleted capital accumulation, investment in human capital, and demographic change to diminished economic growth.

Another popular alternative is the use of the value of statistical life (VSL) approach. This approach is based on the application of willingness-to-pay methods to estimate the overall welfare impact of disease, including both market and non-market effects. VSL models can be seen to complement cost-of-illness estimates as they incorporate a more comprehensive measure of the benefits of living in good health, which includes the value of non-market production and consumption, non-labor income, leisure time, and any premiums attached to the avoidance of pain and suffering. Nonetheless, a number of important restrictions limit the applicability of VSL models, particularly in the case of NCDs, including that: (a) the key parameter (the VSL itself) is 
not observable and subject to extensive debate; (b) the methodology is more readily applicable to mortality as opposed to morbidity impacts; and (c) the economic impact estimates are not bounded and can generate extreme results with difficult interpretation.

An augmented Solow model, which assumes that national income depends on the capital stock, the labor force size, and aggregate measures of human capital, is the basis for the WHO EPIC model applied in this paper. EPIC treats health, as indicated by NCD prevalence, as a central component of human capital, relying on estimates of the impact of NCDs from microeconomic studies and using them to calibrate the size of the effects at the aggregate level (Bloom \& Canning, 2008). This approach is very flexible and suitable for applications with limited data availability. Moreover, since it is based on structural production functions it avoids many of the issues that affect other empirical models of economic growth. The results can also be used to decompose the differences in GDP across countries into input factors as implied by the aggregate production function.

\subsection{Pathways for the impact of NCDs on GDP}

Dynamic macroeconomic models usually represent the economy as a system of complex interactions between three main types of agents: households, firms, and the government, where the last is often omitted for the sake of analytical tractability and a clearer exposition. Economic growth depends on the key production factors, capital, labor, and technology, that affect the flow of income between the agents within the system. If injections of these production factors are greater (or conversely, smaller) than leakages like depreciation, then total output increases (or decreases). In the equilibrium of a simple closed economy model without government, aggregate income of all economic agents is equal to aggregate expenditure plus aggregate savings.

In such a framework, NCDs affect economic growth through three main channels (World Health Organization, 2009). First, NCDs can increase health expenditures for all three types of agents. For households, NCD treatment and care expenses can force them to reduce consumption of non-

health items as well as savings and investment. This is especially the case in developing countries with limited systems of health coverage and where household consumption is often quite close to subsistence level. For firms, NCDs can affect the amount of available income, 
given the need to pay for premiums and social insurance contributions to protect the wellbeing of their workers.

The second channel of NCDs' macroeconomic impact operates through labor and productivity losses. The direct labor supply impact reduces the number of working-age individuals, due to both increased mortality and reduced on-the-job productivity for the sick. If employees die or suffer from a disease that reduces their productivity, then their corresponding contribution to total output is lost for the economy. By contrast, if people who do not work (retirees, children, etc.) suffer from the same illnesses, total output stays unaffected. ${ }^{3}$ Therefore it is important to know the extent to which employees are differentially affected by the corresponding illnesses. Indirect productivity impacts can take the form of reduced cognitive abilities and increased absenteeism and worker turnover. Both direct and indirect impacts can also lead to ripple effects, such as reduced household earnings and firms' reluctance to invest in workers' training and capacity development, which can in turn further hinder economic growth.

Finally, NCDs affect the incentives for savings and for investment in both physical and human capital. NCDs can force people into early retirement, therefore reducing overall labor market participation and increasing the ratio of dependents to workers. The individuals forced into early retirement often require special medical care and specialized services, which reduce the amount of resources that can be employed in productive activities and exert cost pressures on those firms that provide retiree health care or health insurance. People leaving the workforce must be replaced by new workers, which raises firms' hiring and training costs. Furthermore, the expectation of shorter post-retirement life expectancy can lead to lower savings during active life, which in turn contributes to reducing the stock of physical capital per worker. A related effect reduces incentives to invest in training, education, and other forms of human capital due to shorter payoff periods in the labor market.

\subsection{EPIC model structure, operation, and key parameters}

The modern macroeconomic literature on growth began with Solow (1956), who provides a framework for considering the growth path of national income as explained by physical capital accumulation and exogenously given technological progress. The model was the first to explain

\footnotetext{
${ }^{3}$ Simple accounting shows the following: when an employee dies, per capita GDP shrinks, whereas when a retiree dies, per capita GDP rises. However, we do not make any statements about per capita GDP.
} 
convergence, that is, the empirical regularity that, among countries that share similar structural characteristics (institutions, preferences, etc.), those that are poorer tend to grow faster (c.f. Kaldor, 1957; Barro \& Sala-i-Martin, 1992). The crucial mechanism is the following: in poor countries the capital stock is low and consequently the marginal product of capital is high. Therefore, capital accumulation contributes substantially to economic prosperity in earlier stages of development and during the transition towards being an industrialized, knowledge-based, modern economy. ${ }^{4}$ In developed countries, by contrast, the physical capital stock is already large and its marginal product is therefore low. Physical capital accumulation is thus not the main driving force of growth in this situation. This role is rather assumed by technological progress, which was first endogenously explained within a general equilibrium framework by the seminal contributions of Romer (1990), Grossman and Helpman (1991), and Aghion and Howitt (1992). ${ }^{5}$

Jones (2002) and Keller (2009) emphasize that the G-7 countries were responsible for 84 percent of worldwide R\&D spending in 1995. It is therefore most likely that the research frontier is pushed forward by these countries, and knowledge diffuses from them to poorer ones that did not spend that much on R\&D in the past. When modeling the impact of non-communicable diseases in China and India, we therefore assume that technological progress is exogenous and mainly focus on its influence on the working-age population and physical capital accumulation.

Following Solow (1956), aggregate output in country $i$ at time $t$ is given by

$$
Y_{i, t}=A_{i, t} K_{i, t}^{\alpha} L_{i, t}^{1-\alpha}
$$

where $A$ is an exogenously evolving productivity parameter measuring efficiency in production, that is, the technological level of country $i$ at time $t, K$ is the aggregate physical capital stock (i.e., it represents all the machines and buildings used in the production process), $L$ is the stock of labor in the economy (i.e., it represents all individuals supplying their skills on the labor market),and $\alpha$ denotes the elasticity of final output with respect to capital. The productivity parameter $A$ and the elasticity of final output with respect to capital, $\alpha$ alpha, are both independent of NCDs. The former grows at an exogenously given rate.

\footnotetext{
${ }^{4}$ For a discussion of convergence dynamics, see McQuinn and Whelan, 2007.

5 These endogenous growth models were refined in the next two decades by e.g. Jones (1995), Segerstrom (1998), Peretto (1998), Howitt (1999) and Strulik (2005).
} 
Various extensions have been proposed, such as endogenizing technology (Romer, 1990), and the addition of human capital (Mankiw, Romer, \& Weil, 1993). We adopt the EPIC model developed in Abegunde and Stanciole (2006), and Bloom et al. (2011b). This augments the Solow model by allowing health to impact economic growth via the two paths described above, namely the accumulation of physical capital and the supply of labor. ${ }^{6}$

\subsubsection{Capital accumulation}

First, health care spending diverts resources from productive investment in capital. The aggregate physical capital stock in an economy can then be written as

$$
K_{i, t+1}=s Y_{i, t}-\chi C_{i, t}+(1-\delta) K_{i, t}
$$

where $s$ represents the savings rate (i.e., the fraction of final output invested in the creation of new capital), $C$ represents the treatment costs of the disease, $\chi$ is the fraction of these costs financed out of an individual's savings, and $\delta$ is the rate of depreciation. This equation describes the evolution of the aggregate capital stock, which positively depends on the savings rate and negatively depends on the costs of curing the illness under consideration as well as on the fraction of these costs paid out of savings.

\subsubsection{Evolution of the supply of labor}

Second, labor supply is affected by age-specific disease mortality, so higher prevalence is associated with reductions in the numbers of workers in a particular cohort. The evolution of the labor force is given by the equation

$$
L_{i, t+1}=\sum_{a=15}^{R-1}\left(1-\mu_{t}^{a}\right) L_{i, t}^{a}+\beta_{i, t-14} L_{i, t-14} \prod_{a=1, s=t-(15-a)}^{14}\left(1-\mu_{s}^{a}\right)
$$

where $a$ refers to age, $\mu_{t}^{a}$ represents the cohort specific mortality rate of individuals at age $a, L_{t}^{a}$ is the cohort size of individuals at age $a, \beta_{i, t-14}$ represents the birth rate at time $t-14$, and $R$ is the retirement age. Note that it is assumed that only individuals who are older than 15 years actively participate in the labor market. The first term of this equation represents the evolution of

\footnotetext{
${ }^{6}$ The term "physical" is used to distinguish it from human capital. There is no "financial" capital in the Solow-EPIC model because it is assumed that capital is the only savings vehicle and there is efficient and immediate allocation of household savings toward their most productive uses.
} 
the workforce for all persons who belonged to it in the previous time period and the second term represents the cohort size of the young who are entering the workforce at time $t$. The term in the product adjusts for deaths of children and adolescents up to the age of 15 when the young enter the labor market. NCD-related mortality enters the cohort-specific death rates and therefore exerts its impact on the economy via this second channel. The magnitude of this effect will depend on the structure of mortality rates. The greater the extent to which employees are differentially affected, the more adverse the consequences for GDP per capita (see discussion in section 3.1).

We assume that the world technology frontier grows by 1 percent every year. Consequently, for given capital and labor input, the next year's output will be higher by 1 percent. ${ }^{7}$ The level of the technology parameter has been obtained by calibrating the predicted output of the model for given capital and labor inputs to the actual output in the corresponding country.

The use of an economically founded and accepted framework to assess the macroeconomic impact of non-communicable diseases has some advantages as compared with other standard techniques like the cost-of-illness approach (see Currie, Dymond Kerfoot, Donaldson, \& Macarthur, 2000; Rice, 2000 for its advantages and disadvantages) or the estimation and aggregation of the value of a statistical life - VSL (Viscusi \& Aldy, 2003). First, it takes into account the adjustment mechanisms and dynamics by which economies are characterized. For example, if people die because of a certain disease, this does not lead to a one-for-one drop in output as the cost-of-illness approach and the VSL approach assume. The reason is that other workers (coming either from the pool of unemployed people or from other jobs) and/or capital can be used to substitute for the loss of labor, at least up to a certain extent. Furthermore, as the Solow (1956) model is dynamic in nature, the economic impact of diseases can easily be traced over time, once the mortality patterns as well as the effects of treatment costs on savings are known. Finally, as compared with the VSL approach, the simulation of the Solow (1956) model

\footnotetext{
${ }^{7}$ The EPIC model abstracts from the barriers to technology adoption and diffusion. The model assumes that there is immediate diffusion of new technology (i.e., the parameter A in China grows by the same absolute amount as it grows in the rest of the world), while the level differences in the parameter persist indefinitely.
} 
abstracts from subjective costs and feelings regarding death and thus allows for focus solely on the economic dimension. ${ }^{8}$

\subsection{Data sources}

The estimates are based on WHO projections of the mortality trajectory associated with these five conditions, as well as on WHO estimates of labor force participation rates and imputed rates of technological progress constructed as part of this project.

Data on economic variables were obtained from Abegunde and Stanciole (2006), the World Development Indicators \& Global Development Finance database, the IMF's Global Economic Outlook database, and the Penn World Tables. Demographic and health variables were obtained from UN data on population, and the Global Burden of Disease (GBD) database of WHO.

Results are presented for five conditions in the model (ischemic heart disease, cerebrovascular disease, diabetes, chronic obstructive pulmonary disease (COPD), and breast cancer), which are then scaled up using WHO data on DALYs to reflect the four NCDs that are the focus of the UN (cardiovascular diseases, cancers, chronic respiratory diseases, and diabetes). The scaling is implemented by calculating the proportion of DALYs in a particular domain (e.g., cancer) that are accounted for by the relevant disease in EPIC (breast cancer in this instance). If breast cancer accounts for 10 percent of the total DALYs lost to cancer, the scaling factor applied to the EPIC results for breast cancer to obtain a result for all cancers is 0.1 . Scaling factors are calculated for each country. Similarly, we use WHO data on mental illness DALYs to include estimates of economic losses from mental health conditions. The mental health scaling factor is calculated by obtaining the ratio of DALYs accounted for by the four NCD domains to DALYs accounted for by mental health conditions.

\footnotetext{
${ }^{8}$ The transitional dynamics of the Solow (1956) model and its steady-state properties carry over to the EPIC framework. The only difference from the standard Solow (1956) model is that the savings rate and the population growth rate are now time-varying because they depend on the prevalence of the diseases under consideration. The standard diagram used to characterize the dynamics of the capital stock per unit of effective labor in the Solow (1956) model can be applied with the feature in mind that the curves describing savings on the one hand and depreciation and dilution of capital on the other would not be fixed but move according to the impact of the analyzed NCDs.
} 


\section{Results}

This section presents results from the EPIC model for China and India and the results we find by scaling up to disease categories of the five NCD domains. We examine the time period 20122030 for each country and estimate the cumulative lost economic output from diabetes, cardiovascular diseases, chronic respiratory diseases, cancers, and mental health. We then compare the estimated losses for the two countries. Results are presented on a disease- and country-specific basis in 2010 USD.

\subsection{China}

Table 3 presents the raw output from the EPIC model for China. The EPIC model evaluates the output losses from five specific diseases for the period 2012-2030, namely diabetes, ischemic heart disease, cerebrovascular disease, chronic obstructive pulmonary disease (COPD), and breast cancer. The results are shown in 2010 USD. Of the individual diseases, cerebrovascular disease is the most costly, associated with a loss of almost 2010 USD 4.7 trillion. This is followed closely by COPD at 2010 USD 4.0 trillion. The total (undiscounted) loss associated with these illnesses is USD 11.0 trillion over the whole period. ${ }^{9}$

Table 3.Output losses, 2012-2030, model raw output for China

\begin{tabular}{|l|c|}
\hline \multicolumn{1}{|c|}{ Disease } & $\begin{array}{c}\text { Loss, 2010 USD } \\
\text { (trillions) }\end{array}$ \\
\hline Diabetes & 0.49 \\
\hline Ischemic heart disease & 1.63 \\
\hline Cerebrovascular disease & 4.66 \\
\hline COPD & 4.03 \\
\hline Breast cancer & 0.19 \\
\hline TOTAL & $\mathbf{1 1 . 0}$ \\
\hline
\end{tabular}

\footnotetext{
${ }^{9}$ This exercise compares the outcomes for an economy under two scenarios, with and without the effect of NCDs, and reports the difference in output, summed over a 19-year period. Discounting would affect the amount of the losses from NCDs, but not the fact that the losses would still be substantial. Very roughly, using a $3 \%$ discount rate, the losses reported in the paper would be about $66 \%$ as large as those we report. In the Discussion, where we compare the losses to current outlays that could help avert these losses, we address this issue again.
} 
Table 4 presents results from scaling up these individual diseases to obtain the estimated impact of the five major domains that are the main focus of the recent UN summit on NCDs: diabetes, cardiovascular disease, respiratory disease, cancer, and mental health. We use estimates of DALYs, which allows us to assess the contribution of each disease in the EPIC model to each of these five types of NCD. The scaling factors reflect country-specific estimates from the Global Burden of Disease 2004 Update study (World Health Organization, 2008). ${ }^{10}$

The first column shows each of the five WHO-defined disease domains, while the second shows the diseases addressed by the EPIC model. The third shows the raw output for physical illness. The contributions of ischemic heart disease and cerebrovascular disease are summed to obtain the burden associated with cardiovascular disease. Next, the burdens for the four main NCD disease domains are obtained by applying the scaling factors associated with each individual NCD in column 4 to the totals in column 3. The final column shows the scaled raw output. Finally, the mental health burden is obtained by applying the DALY-derived scaling factor to the scaled total of the four physical health conditions. The total losses associated with physical disease and mental health are USD 18.4 trillion and USD 9.4 trillion, respectively.

\footnotetext{
${ }^{10}$ See the Appendix for early estimates of output losses using the 2010 update of GBD. Notably, the 2010 data suggest lower losses from mental health than we present in the body of this paper.
} 
Table 4. Scaling of EPIC output for 2012-2030

to match five WHO NCD domains for China

(trillions of 2010 USD)

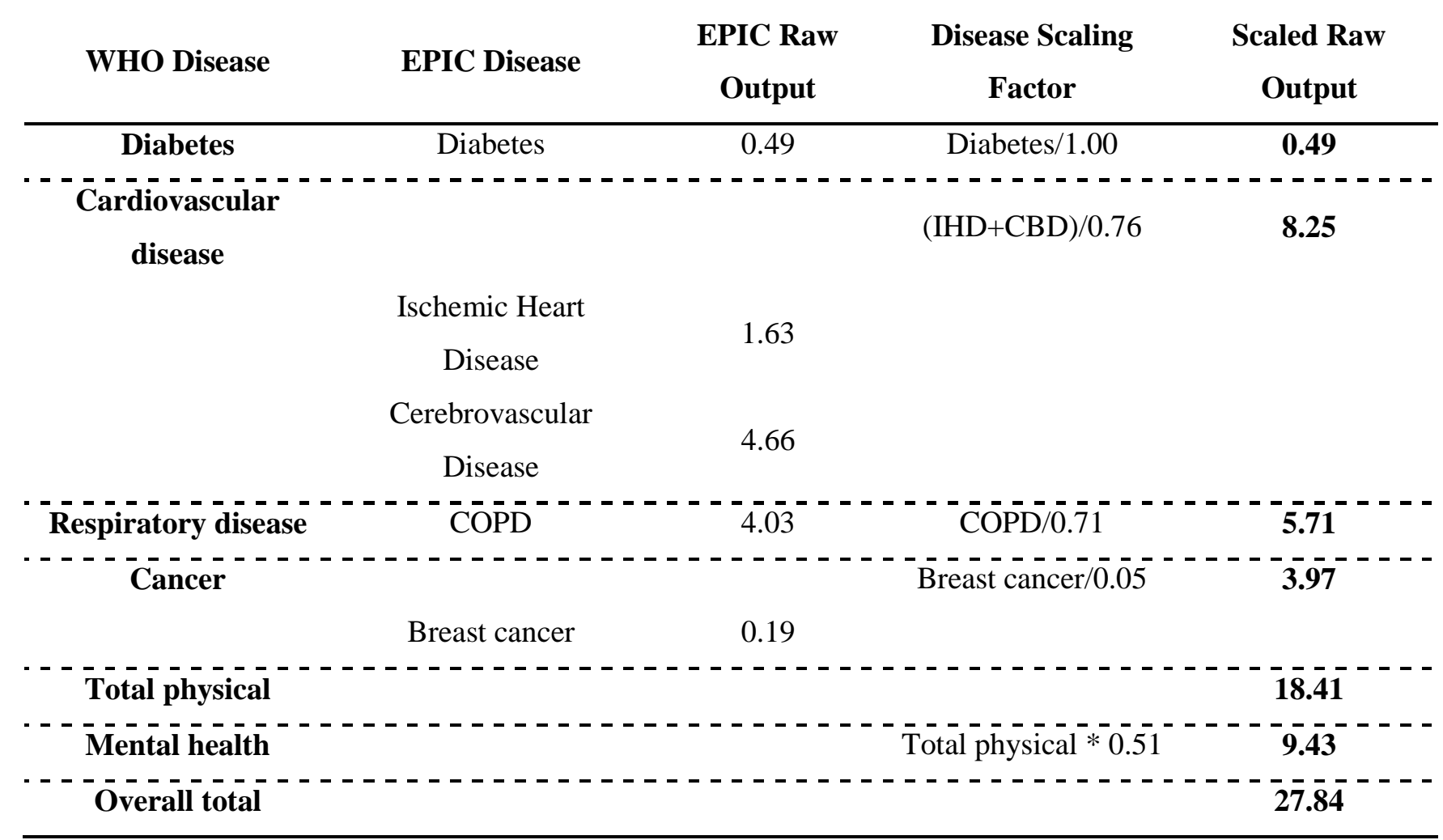

Figure 6 shows the contribution of each of these domains to the total for the same period. Mental health is the largest category, followed by cardiovascular diseases and respiratory disease. The economic costs of diabetes are estimated to be relatively small ( 2 percent), perhaps because diabetes leads to other conditions (e.g., cardiovascular disease) that are ultimately recorded as the cause of missed work and death. It is important to note that although small relative to the others, the absolute losses associated with diabetes and cancer are very high. 
Figure 6. Contribution of each disease to overall lost output for China

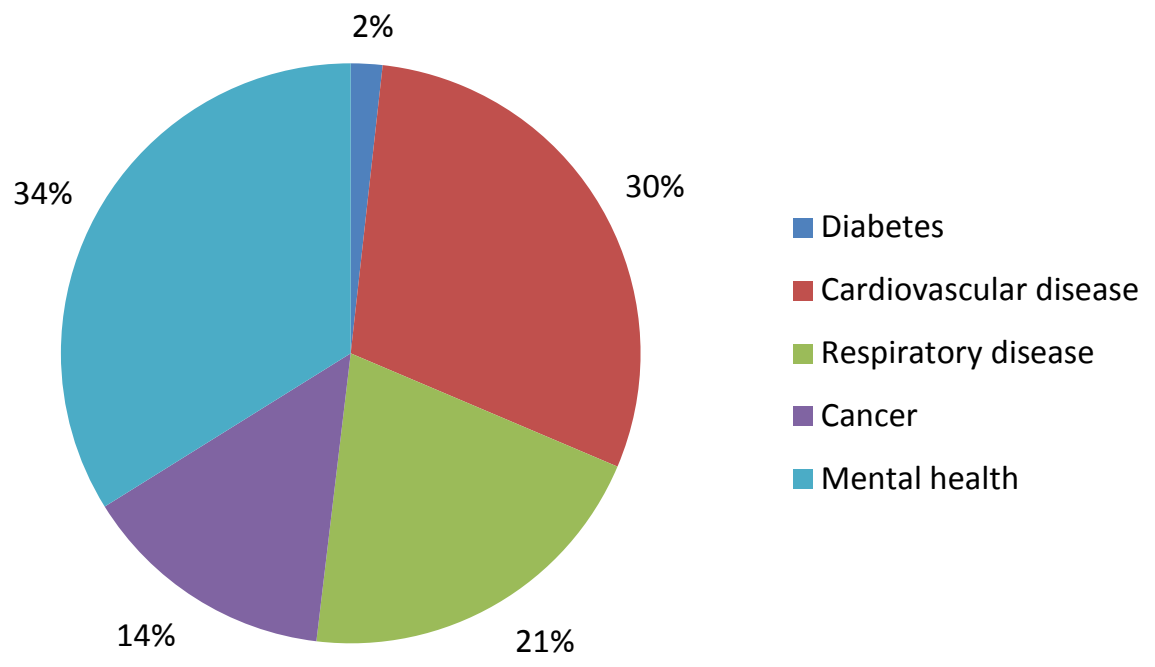

\subsection{India}

Table 5 presents results for the raw output of the EPIC model for India. Ischemic heart disease is estimated to be the single most costly NCD, followed by COPD. The total loss associated with the five specific diseases is USD 2.6 trillion.

Table 5.Output losses, 2012-2030, model raw output for India

\begin{tabular}{|l|c|}
\hline \multicolumn{1}{|c|}{ Disease } & $\begin{array}{c}\text { Loss, 2010 USD } \\
\text { (trillions) }\end{array}$ \\
\hline Diabetes & 0.15 \\
\hline Ischemic heart disease & 1.21 \\
\hline Cerebrovascular disease & 0.49 \\
\hline COPD & 0.71 \\
\hline Breast cancer & 0.02 \\
\hline TOTAL & $\mathbf{2 . 5 8}$ \\
\hline
\end{tabular}


Table 6 shows the results from scaling up each disease in the EPIC model to the five WHO categories. The scaling factors reflect results from the Global Burden of Disease 2004 Update study on India (World Health Organization, 2008). The total losses associated with physical disease and mental health are USD 3.9 trillion and USD 2.3 trillion, respectively.

Table 6. Scaling of EPIC output for 2012-2030

to match five WHO NCD domains for India

(trillions of 2010 USD)

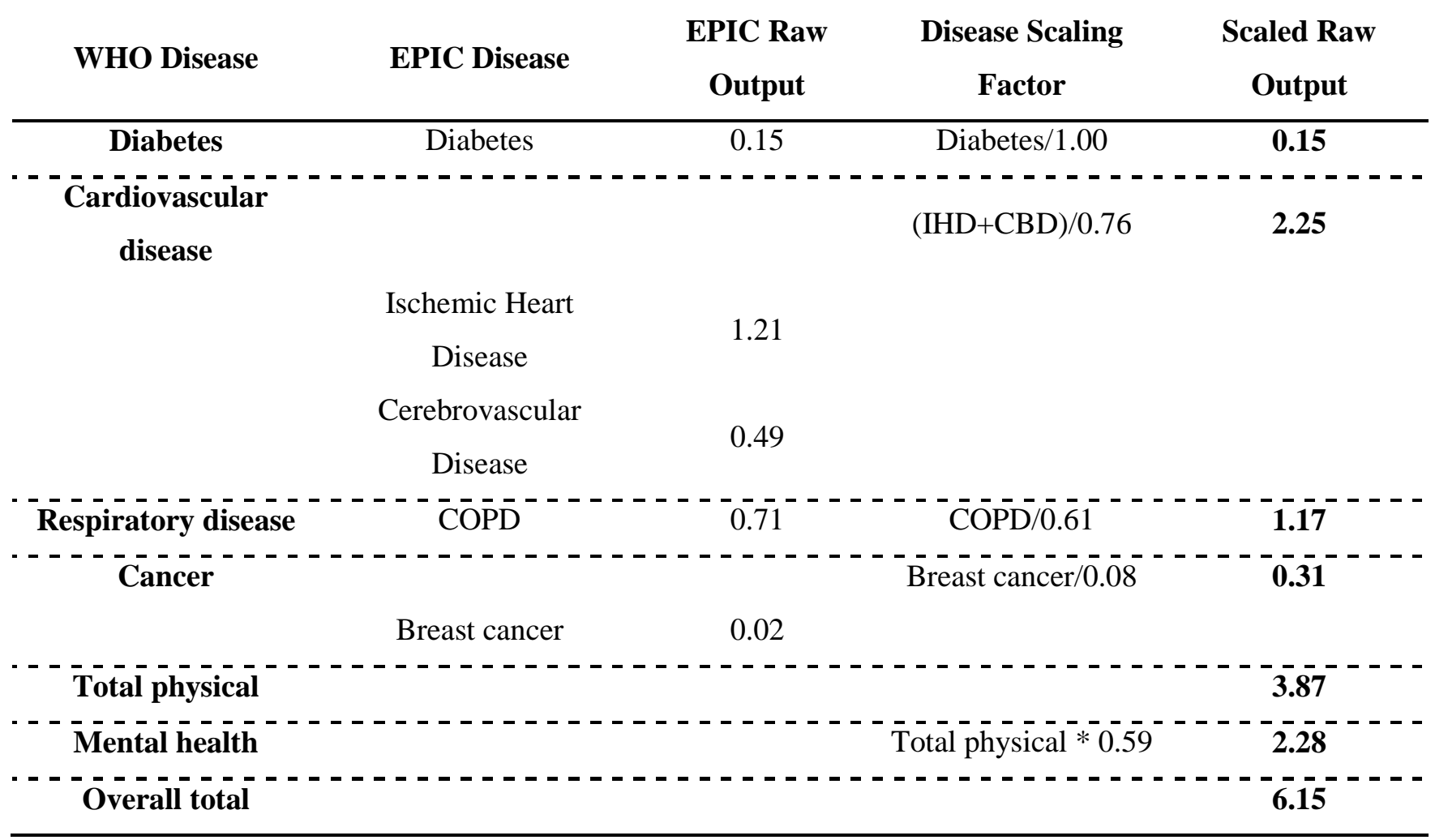

Figure 7 shows the relative contribution of each disease domain to the total figure. Cardiovascular disease is the largest category, closely followed by mental health and then respiratory disease. The losses attributable to diabetes and cancer are relatively small in comparison. 


\section{Figure 7. Contribution of each disease to overall lost output for India}

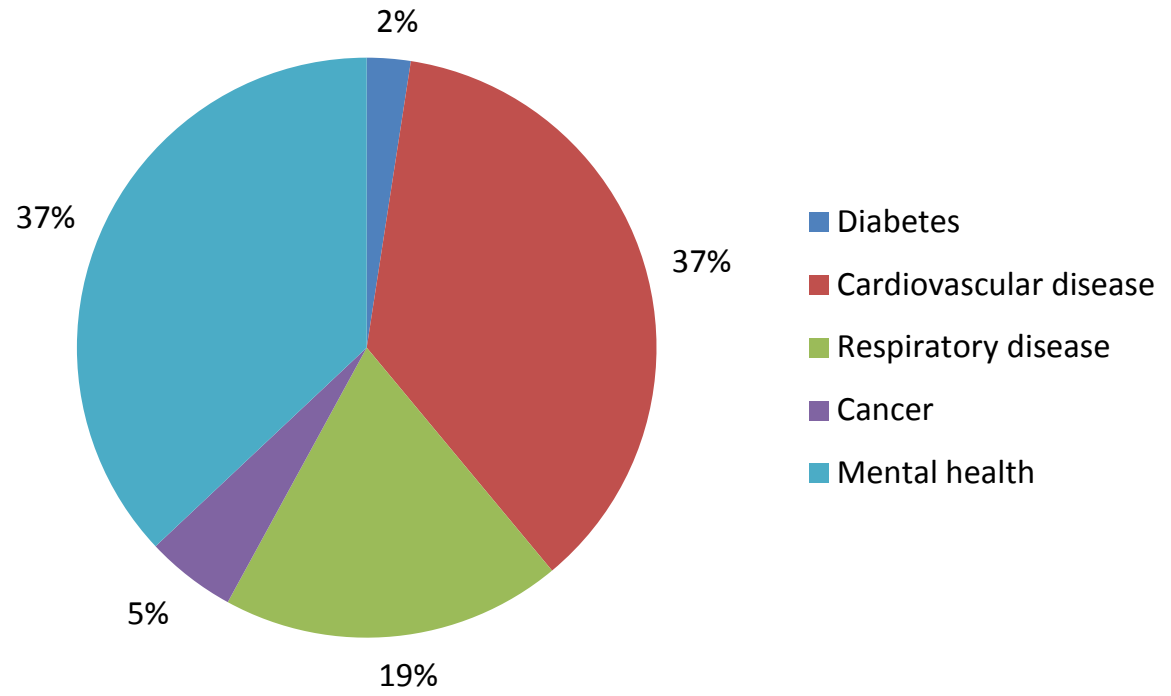

\subsection{Comparison of China and India}

Figure 8 presents results comparing the estimated losses for each disease in China and India for the period 2012-2030. The cost associated with each domain is substantially higher for China than India. These disparities arise largely due to the difference in the initial level of GDP in the two countries and secondarily to the projected difference in GDP through 2030 (which are based on IMF estimates). This is due to the structure of the model, in which reductions in labor supply or capital formation are most costly at higher levels of GDP. For a comparison of the economic burden of disease in high-, middle-, and low-income countries, see Bloom, et al. (2011b). 
Figure 8. Comparison of lost output for China and India, 2012-2030

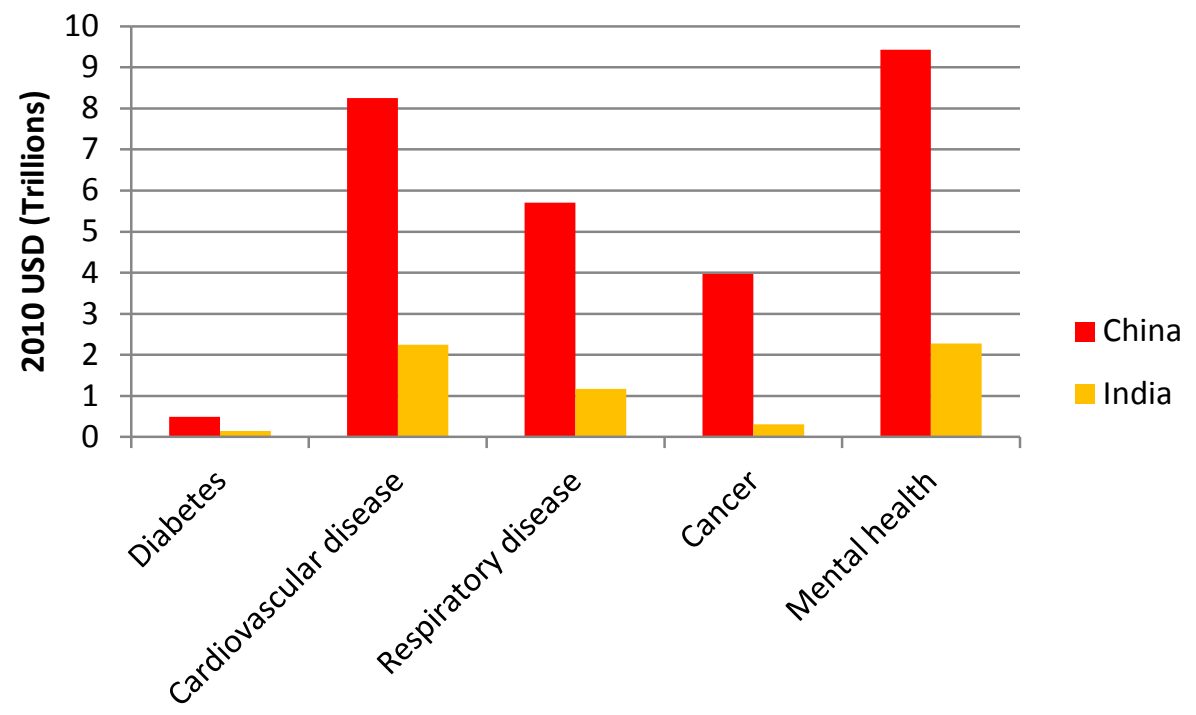

In both countries, the economic costs of diabetes are estimated to be a very small fraction of the total losses from NCDs. However, it is important to note that the absolute losses associated with all five of these disease categories are high in both China and India. Furthermore, the values for diabetes are understated since it is not typically fatal on its own, but often leads to cardiovascular disease and other health problems that carry a high burden of mortality, such as kidney disease.

\section{Discussion}

The results from the EPIC model suggest that the magnitude of the losses associated with noncommunicable diseases is significant for India, and even more so for China. However, these figures refer to the economic costs over the course of a 19-year period, and therefore it is important to put these numbers in context. Bearing in mind that the estimates made in this report are intended to give only a very rough sense of the economic burden, we can compare the estimates to the approximate total health expenditure in the two countries during the previous 19year period. For China, we estimate the total economic burden, from 2012-2030, to be 27.8 trillion (in 2010 USD). This figure swamps the total health expenditure in China during the 
previous 19 years, which was approximately USD 2.2 trillion. For India, the corresponding figures are USD 6.2 trillion and USD 710 billion. $^{11}$

In economic terms, the savings from reducing the incidence of NCDs could be substantial. Bloom et al. (2011c) find that implementation of these "best buy" interventions for reducing NCDs in low- and middle-income countries (LMICs) could lead to a 10-15 percent reduction in premature death from NCDs (and in their economic costs). Using as an example a 12.5 percent reduction in mortality from ischemic heart disease and stroke in LMICs, Bloom et al. (2011c) find that economic savings would be USD 25 billion per year over the period 2011-2025. If the same 12.5 percent reduction in mortality (and costs) is assumed for all four disease categories covered in the report (diabetes, cardiovascular disease, respiratory diseases, and cancer), the annual savings would equal roughly USD 50 billion.

The same reasoning can be extended to China and India. Applying the 12.5 percent reduction assumption used in the report, China could expect to decrease its economic losses from cardiovascular disease over the period 2012-2030 by USD 1.03 trillion, or USD 54 billion per year. If the same calculation is applied to all of the NCD categories (with the exception of mental health, because the "best buys" do not address mental health), the reduction in losses would be USD 2.3 trillion in total, or 121 billion per year. For India, cardiovascular disease savings would be USD 15 billion per year, and total savings would be USD 25 billion per year. For China, the cost of implementing these best buys is approximately USD 4 billion per year; the corresponding cost for India is USD 1.7 billion. (The cost data are from Bloom et al., 2011c.) For both countries, these rough estimates of benefit-cost ratios are extremely favorable and well in excess of $10 .^{12}$ Thus, WHO's best buys are expensive to implement, but more expensive not to implement.

\section{Conclusion}

This paper summarizes the economic costs associated with NCDs in China and India over the period 2012-2030. Results are obtained using EPIC, which augments the standard Solow

\footnotetext{
${ }^{11}$ Data on health expenditures are from the World Bank Development Indicators: http://data.worldbank.org/indicator.

${ }^{12}$ If we used discounted figures, which would be required in a benefit-cost analysis, the benefit-cost ratios would be lower, by roughly $66 \%$.
} 
economic growth model to incorporate health effects into national income via mortality effects on cohort size and the diversion of savings from productive capital formation into unproductive health care spending. Models of the economy are simulated in which we forecast future disease prevalence on the basis of current trends. This projection is then compared to a scenario in which disease prevalence is reduced to zero. Comparing the differences in output between these two scenarios allows for the estimation of the costs of a particular disease. Results are obtained for five domains, based on scaling from the WHO Global Burden of Disease database: cardiovascular diseases, cancers, chronic respiratory diseases, diabetes, and mental health.

We find that the costs associated with NCDs in both China and India are substantial, both in absolute terms and relative to other indicators such as the flow of expenditure on health care in a given year in each country. For China, the cumulative cost associated with each of the five domains (cardiovascular disease, cancer, chronic respiratory disease, diabetes, and mental health) is USD 27.84 trillion; for India, the cumulative cost is USD 6.15 trillion (both figures in USD 2010). The larger result for China reflects the facts that China has an older population and that in general losses are greater when GDP is higher. The most important NCD for each country is cardiovascular disease.

The EPIC tool captures two very important channels by which mortality in general and noncommunicable diseases in particular can affect the economic performance of a country. The first channel is represented by the adverse effect of treatment costs on savings and thereby on capital accumulation, while the second channel is represented by the impact of disease-specific mortality on the effective labor force of a country. Since understanding both the development of the workforce and the evolution of the capital stock of a country are crucial to assessing its medium- and long-run economic performance, the current framework represents a step toward a more economically founded assessment of the macroeconomic impact of diseases than the standard cost-of-illness approach or the VSL approach.

Nevertheless, we acknowledge that there is room for further improvements and refinements. For the sake of tractability we abstracted from more complex models of the economy, and other important channels by which diseases can exert their influence. To mention only the most important ones: diseases can affect schooling attendance and performance and thereby human capital accumulation, which is itself an important driving force of economic growth (cf. Lucas 
1988, Mankiw et al., 1993); diseases can also hamper the ability of an economy to benefit from international knowledge spillovers (cf. Parente \& Prescott, 1994); furthermore, a fraction of the treatment costs of illnesses might be financed by the government via distortionary taxation. In addition, by focusing on total NCD prevalence, the model estimates how much economic benefit could be derived from completely eliminating the diseases. In reality, the gradual nature of NCD development and the difficulty in reversing long-term trends in risk factors, among other things, put a limit on how much of the economic impact can be avoided. Thus the magnitude of the impact estimated through the model should be considered only indicative. More appropriate estimates to guide policy decisions, probably based on measures of avertable incidence, need to be developed.

An additional limitation of the model is that, in addition to mortality, it does not explicitly address the impact of NCDs on morbidity. Currently, the model simply assumes that sick individuals either do not work or die instantaneously; there is no spectrum of productivity associated with the severity or type of illness. A possible solution might involve the use of disability weights as a way to control for NCDs' productivity impact on labor supply (Weil, 2010). A related issue is whether the relative financial cost of an illness in a particular category (e.g., cancer) can be accurately captured using the DALY weights. For example, if breast cancer represents 10 percent of the total DALYs associated with cancer, we assume that it represents 10 percent of total cancer costs. This is potentially problematic, but is necessary as we currently only have cost of treatment information for a limited number of conditions. Obtaining more comprehensive data on health care costs should be a priority for future research. Extending the model to allow examination of the distribution of NCD costs would also be useful. 


\section{References}

Abegunde, D., \& Stanciole, A. (2006).An estimation of the economic impact of chronic noncommunicable diseases in selected countries. World Health Organization, Department of Chronic Diseases and Health Promotion.

Abegunde, D. O., Mathers, C. D., Adam, T., Ortegon, M., \& Strong, K. (2007).The burden and costs of chronic diseases in low-income and middle-income countries. The Lancet, 370(9603), 1929-1938.

Aghion P., \& Howitt, P. (1992).A model of growth through creative destruction. Econometrica, 60(2), 323-351.

Baja, V. (2012, July 7). India's poor to benefit from free drugs; Government to propose distribution of generics, a blow to big companies, International Herald Tribune.

Barro, R. J., \& Sala-i-martin, X. (1992).Convergence. Journal of Political Economy,100(2), 223-251.

Becker, G. S., Philipson, T. J., \& Soares, R. R. (2005).The quantity and quality of life and the evolution of world inequality. The American Economic Review, 95(1), 277-291. doi: $10.2307 / 4132680$

Bloom, D. E., Canning, D., \& Sevilla, J. (2004). The effect of health on economic growth: A production function approach. World Development, 32(1), 1-13. doi: http://dx.doi.org/10.1016/j.worlddev.2003.07.002

Bloom, D. E. \& Canning, D. (2008).Population health and economic growth. Background paper for the Commission on Growth and Development. Washington, DC: World Bank.

Bloom, D. E., Canning, D., Hu, L., Liu, Y., Mahal, A., \& Yip, W. (2010).The contribution of population health and demographic change to economic growth in China and India. Journal of Comparative Economics, 38(1), 17-33. doi: 10.1016/j.jce.2009.11.002

Bloom, D. E. (2011a).7 billion and counting. Science, 333(6042), 562-569. doi: $10.1126 /$ science. 1209290 
Bloom, D. E., Cafiero, E.T., Jané-Llopis, E., Abrahams-Gessel, S., Bloom, L. R., Fathima, S., Feigl, A.B., Gaziano, T., Mowafi, M., Pandya, A., Prettner, K., Rosenberg, L., Seligman, B., Stein, A., and Weinstein, C. (2011b).The global economic burden of noncommunicable diseases. Geneva: World Economic Forum.

Bloom, D. E., Dan Chisholm, Eva Jané-Llopis, Klaus Prettner, Adam Stein, and Andrea Feigl. (2011c). From burden to "Best Buys": Reducing the economic impact of noncommunicable diseases in low-and middle-income countries. Geneva: World Economic Forum.

Bloom, D.E., Canning, D., \& Fink, G. (in press). Disease and Development Revisited .Journal of Political Economy.

Centers for Disease Control and Prevention. (2013, July 9). Smoking and Tobacco Use: Bidis and Kreteks. Retrieved from: http://www.cdc.gov/tobacco/data_statistics/fact_sheets/tobacco_industry/bidis_kreteks/

Currie, G., Dymond Kerfoot, K., Donaldson, C., \& Macarthur, C. (2000). Are cost of injury studies useful? Injury Prevention, 6, 175-176.

Dey, S., Nambiar, D., Lakshmi, J. K., Sheikh, K., \& Reddy, K. S. (2012). Health of the Elderly in India: Challenges of Access and Affordability. In .P. Smith and M. Majmundar, (Eds.), Aging in Asia: Findings from new and emerging data initiatives(pp. 371-386). Washington, DC: National Academies Press.

Dudeja V., Misra A., Pandey R.M., Devina G., Kumar G., \& Vikram N.K. (2001). BMI does not accurately predict overweight in Asians in northern India. British Journal of Nutrition, $86,105-12$.

Dwyer, D. S., \& Mitchell, O. S. (1999). Health problems as determinants of retirement: Are selfrated measures endogenous? Journal of Health Economics, 18(2), 173-193. doi: http://dx.doi.org/10.1016/S0167-6296(98)00034-4 
Express News Service. (2013, June 1). Karnataka becomes 26th state to ban gutkha, The New Indian Express. Retrieved from http://newindianexpress.com/states/karnataka/Karnatakabecomes-26th-state-to-ban-gutkha/2013/06/01/article1615107.ece

Evans, J.M., Kiran, P.R., \& Bhattacharyya, O.K. (2011).Activating the knowledge-to-action cycle for geriatric care in India. Health Res Policy Syst. 9:42. doi: 10.1186/1478-4505-942.

Ferlay, J., Shin, H.R., Bray, F., Forman, D., Mathers, C, \& Parkin, D.M. (2013). GLOBOCAN 2008 v2.0, Cancer Incidence and Mortality Worldwide: IARC Cancer Base No. 10 [Internet].Lyon, France: International Agency for Research on Cancer. Retrieved from: http://globocan.iarc.fr, accessed on 2/7/13.

Gao, S., Zheng, R., \& Hu, T. (2012). Can increases in the cigarette tax rate be linked to cigarette retail prices? Solving mysteries related to the cigarette pricing mechanism in China. Tobacco Control, 21, 560-562.

Goel, S., Ravindra, K., Singh, R. J., \& Sharma, D. (2013). Effective smoke-free policies in achieving a high level of compliance with smoke-free law: Experiences from a district of North India. Tobacco Control, 1-4. Retrieved from: http://www.ncbi.nlm.nih.gov/pubmed/23322311.

Grossman G. M., \& Helpman, E. (1991). Quality ladders in the theory of economic growth. Review of Economic Studies,58(1), 43-61.

Gu, D., Reynolds, K., Wu, X., Chen, J., Duan, X., Muntner, P., ...\& He, J. (2002). Prevalence, awareness, treatment, and control of hypertension in China. Hypertension, 40(6), 920927. Retrieved from: http://hyper.ahajournals.org/cgi/doi/10.1161/01.HYP.0000040263.94619.D5.

Howitt, P. (1999). Steady endogenous growth with population and R\&D inputs growing. Journal of Political Economy, 107(4), 715-730.

Institute for Health Metrics and Evaluation. (2013a). Global Burden of Disease Country Profiles: China. Retrieved from: 
http://www.healthmetricsandevaluation.org/sites/default/files/countryprofiles/GBD\%20Country\%20Report\%20-\%20China.pdf

Institute for Health Metrics and Evaluation. (2013b). Global Burden of Disease Country Profiles: India. Retrieved from: http://www.healthmetricsandevaluation.org/sites/default/files/countryprofiles/GBD\%20Country\%20Report\%20-\%20India.pdf

International Institute for Population Sciences. (2005-2006).National Family Health Survey (NFHS-3).Retrieved from: http://pdf.usaid.gov/pdf_docs/PNADK385.pdf

John, R. M., Rao, R. K., Rao, M.G., Moore, J., Deshpande, R. S., Sengupta, J., ... \& Jha, P. (2010).The Economics of Tobacco and Tobacco Taxation in India.Retrieved from: http://global.tobaccofreekids.org/files/pdfs/en/India_tobacco_taxes_report_en.pdf.

Jones, C. I. (1995). R\&D-based models of economic growth. Journal of Political Economy, 103(4), 759-783.

Jones, C. I. (2002). Sources of U.S. economic growth in a world of ideas. American Economic Review, 92(1), 220-239.

Kaldor, N. (1957). A model of economic growth. The Economic Journal,67(268), 591-624.

Kearney, P. M., Whelton, M., Reynolds, K., Muntner, P., Whelton, P. K., \& He, J. (2005).Global burden of hypertension: Analysis of worldwide data. The Lancet, 365(9455), 217-223. doi: 10.1016/s0140-6736(05)17741-1.

Keller, W. (2009).International trade, foreign direct investment, and technological spillovers (Working Paper No. 15442). Cambridge, MA: National Bureau of Economic Research.

Liu, B. Q., Peto, R., Chen, Z. M., Boreham, J., Wu, Y. P., Li, J. Y., ... \& Chen, J. S. (1998). Emerging tobacco hazards in China: 1. Retrospective proportional mortality study of one million deaths. BMJ: British Medical Journal, 317(7170), 1411.

Lopez-Casasnovas, G., Rivera, B., \& Currais, L. (2005).Health and economic growth: findings and policy implications. Cambridge, MA: MIT Press. 
Lozano, R., Naghavi, M., Foreman, K., Lim, S., Shibuya, K., Aboyans, V., ...\& Murray, C.J.L. (2012). Global and regional mortality from 235 causes of death for 20 age groups in 1990 and 2010: a systematic analysis for the Global Burden of Disease Study 2010. The Lancet, 380(9859), 2095-2128.

Lucas, R. (1988). On the mechanics of economic development. Journal of Monetary Economics,22(1), 3-42.

Ma, J., Apelberg, B. J., Avila-Tang, E., Yang, G., Ma, S., Samet, J. M., \& Stillman, F. A. (2010). Workplace smoking restrictions in China: results from a six county survey. Tobacco control, 19(5), 403-409.

Mankiw, N. G., Romer, D., \& Weil, D. N. (1992).A contribution to the empirics of economic growth. The quarterly journal of economics, 107(2), 407-437.

Marrero, S. L., Bloom, D. E., \& Adashi, E. Y. (2012). Noncommunicable diseases: A global health crisis in a new world order. The Journal of the American Medical Association, 307(19), 2037-2038.

McGarry, K. (2004). Health and retirement: Do changes in health affect retirement expectations? Journal of Human Resources, 39(3), 624.

McQuinn, K.,\& Whelan, K.(2007).Conditional convergence and the dynamics of the capitaloutput ratio. Journal of Economic Growth,12(2), 159-184.

Mendis, S. (2007). The availability and affordability of selected essential medicines for chronic diseases in six low- and middle-income countries. Bulletin of the World Health Organization,85(4), 279-288. Retrieved from: http://www.who.int/bulletin/volumes/85/4/06-033647.pdf.

Ministry of Health and Family Welfare. (2008). Bidi Smoking and Public Health. New Delhi: Ministry of Health and Family Welfare, Government of India.

Murray, C. J. L., Ezzati, M., Flaxman, A. D., Lim, S., Lozano, R., Michaud, C., ...\& Lopez, A. D. (2012a). GBD 2010: Design, definitions, and metrics. The Lancet, 380(9859), 20632066. doi: http://dx.doi.org/10.1016/S0140-6736(12)61899-6 
Murray, C. J., Vos, T., Lozano, R., Naghavi, M., Flaxman, A. D., Michaud, C., ...\& Brooker, S.(2012b). Disability-adjusted life years (DALYs) for 291 diseases and injuries in 21 regions, 1990-2010: A systematic analysis for the Global Burden of Disease Study 2010. The Lancet, 380(9859), 2197-2223.

National Sample Survey Organisation. (2006). Morbidity, Health Care and the Condition of the Aged. National Sample Survey, 60th Round, (Report no. 507 (60/25.0/1).New Delhi: Ministry of Statistics and Programme Implementation, Government of India.

Parasuraman S., et al. (2005-2006).A Profile of Youth in India. National Family Health Survey (NFHS-3). Mumbai:International Institute for Population Sciences.

Parente, S. L., \& Prescott, E. C. (1994).Barriers to Technology Adoption and Development. Journal of Political Economy, 102(2), 298-321.

Peretto, P.F. (1998).Technological change and population growth. Journal of Economic Growth,3(4), 283-311.

Popkin, B. M., Horton, S., Kim, S., Mahal, A., \& Shuigao, J. (2001). Trends in diet, nutritional status, and diet-related noncommunicable diseases in China and India: The economic costs of the nutrition transition. Nutrition Reviews,59(12), 379-390. Retrieved from: http://www.ncbi.nlm.nih.gov/pubmed/11766908

Press Information Bureau. (2013, July 2). Health Warnings on Tobacco

Products.[Pictorial/Graphic.ID :95088]. New Delhi: Government of India. Available from: http://pib.nic.in/newsite/erelease.aspx ?relid=95088

Rice, D.P. (2000). Cost of illness studies: What is good about them? Injury Prevention, 6, 177179.

Romer, P. (1990).Endogenous technological change. Journal of Political Economy,98(5), 71102.

Salomon, J. A., Wang, H., Freeman, M. K., Vos, T., Flaxman, A. D., Lopez, A. D., \& Murray, C. J. L. (2012). Healthy life expectancy for 187 countries, 1990-2010: A systematic analysis for the Global Burden Disease Study 2010. The Lancet, 380(9859), 2144-2162. 
Segerstrom, P.M. (1998). Endogenous growth without scale effects. American Economic Review, 88(5), 1290-1310.

Singha, K. (2012, September 28). Government to bring essential medicines under price control, The Times of India.

Solow, R. M. (1956). A contribution to the theory of economic growth. The Quarterly Journal of Economics, 70(1), 65-94.

Strauss, J., Hong, H., Lei, X., Li, L., Park, A., Yang, L., \& Zhao, Y. (2012). Healthcare and insurance among the elderly in China: Evidence from the CHARLS pilot. In .P. Smith and M. Majmundar, (Eds.), Aging in Asia: Findings from new and emerging data initiatives(pp. 342-370). Washington, DC: National Academies Press.

Strulik, H. (2005). The role of human capital and population growth in the theory of economic growth. Review of International Economics, 13(1), 129-145.

Van Mourik, M. S., Cameron, A., Ewen, M., \& Laing, R. O. (2010). Availability, price and affordability of cardiovascular medicines: A comparison across 36 countries using WHO/HAI data. BMC Cardiovascular disorders, 10(1), 25. Retrieved from: http://www.pubmedcentral.nih.gov/articlerender.fcgi?artid=2898673\&tool=pmcentrez\&r endertype $=$ abstract.

Viscusi, W. K., \& Aldy, J. E. (2003). The value of a statistical life: A critical review of market estimates throughout the world. Journal of Risk and Uncertainty, 27(1), 5-76.

Wan, X., Ma, S., Hoek, J., Yang, J., Wu, 1., Zhou, J. \& Yang, G. (2012).Conflict of interest and FCTC implementation in China. Tobacco Control, 21, 412-5.

Weil, D. (2010). Endemic diseases and African economic growth: Challenges and policy responses. Journal of African Economies, 19(AERC Supplement 3), iii81-iii109.doi: 10.1093/jae/ejq018.

Williams, R.,\& Krakauer, R,. (2011). The challenge of non-communicable diseases and geriatric conditions.In Global Populatin Ageing: Peril or Promise?Geneva: World Economic Forum. 
Wolf, C., Dalal, S., DaVanzo, J., Larson, E. V., Akhmedjonov, A., Dogo, H., \& Montoya, S. (2011). China and India, 2025: A comparative assessment. RAND.

World Health Organization. (2008). The global burden of disease: 2004 update. Geneva: World Health Organization.

World Health Organization. (2009). WHO guide to identifying the economic impact of disease and injury. Geneva: World Health Organization.

World Health Organization. (2011a). Global status report on alcohol and health 2011. Geneva: World Health Organization.

World Health Organization. (2011b). Global status report on noncommunicable diseases 2010. Geneva: World Health Organization.

World Health Organization. (2011c). WHO NCD Country Profiles. Geneva: World Health Organization.

World Health Organization. (2011d). [Graph illustration of percentage of all NCD deaths occurring under the age of 70, 2008]. WHO Global Health Observatory. Retrieved from http://gamapserver.who.int/gho/interactive_charts/ncd/mortality/premature/atlas.htm

Zhao, Y., Park, A., Strauss, J., Giles, J., Mao, S., Crimmins, E., ...\& Yin, X., (2013). Challenges of population aging in China: Evidence from the national baseline survey of the China Health and Retirement Longitudinal Study (CHARLS). Beijing: National School of Development, Peking University. 


\section{Appendix}

Tables A-1 and A-2 provide a preliminary alternate scaling of the EPIC Output for 2012-2030 based on the new GBD 2010 data. Country-level data are not yet available, ${ }^{13}$ so the values for East Asia and South Asia are used to construct the scaling factors from the output of the EPIC model to the overall burden of WHO NCD domains. It is apparent from Tables A-1 and A-2 that the conclusion that NCDs will impose a sizable economic burden on both China and India remains robust to this change in data source. One potentially notable difference is the larger burden of cancer for China in this estimate, which likely reflects the fact that breast cancer (the EPIC measurement that was scaled up) is a smaller proportion of total cancer in East Asia due to the high prevalence of smoking in comparison to all upper-middle-income countries. A larger difference worth noting is that the GBD 2010 data yield a substantially lower estimated burden for mental health, which likely reflects changes in GBD measurement and weighting rather than changes in the actual burden of mental illness.

\footnotetext{
${ }^{13}$ Country-level GBD 2010 data will be made available in September 2013
} 
Table A-1. Scaling of EPIC Output for 2012-2030

to Match Five WHO NCD Domains for China

GBD 2010

(trillions of 2010 USD)

EPIC

Scaled

\begin{tabular}{|c|c|c|c|c|}
\hline $\begin{array}{c}\text { WHO } \\
\text { Disease }\end{array}$ & EPIC Disease & $\begin{array}{c}\text { EPIC } \\
\text { Raw } \\
\text { Output }\end{array}$ & $\begin{array}{c}\text { Disease Scaling } \\
\text { Factor }\end{array}$ & $\begin{array}{c}\text { Scaled } \\
\text { Raw } \\
\text { Output }\end{array}$ \\
\hline Diabetes & Diabetes & 0.49 & Diabetes/1.00 & 0.49 \\
\hline $\begin{array}{l}\text { Heart } \\
\text { disease }\end{array}$ & & & $(\mathrm{IHD}+\mathrm{CBD}) / 0.82$ & 7.63 \\
\hline
\end{tabular}

Ischemic Heart 1.63

Disease

Cerebrovascular $\quad 4.66$

Disease

\begin{tabular}{|c|c|c|c|c|}
\hline $\begin{array}{c}\text { Respiratory } \\
\text { disease }\end{array}$ & COPD & 4.03 & COPD/0.84 & 4.81 \\
\hline \multirow[t]{2}{*}{ Cancer } & & & $\begin{array}{c}\text { Breast } \\
\text { cancer/0.034 }\end{array}$ & 5.51 \\
\hline & Breast cancer & 0.19 & & \\
\hline $\begin{array}{c}\text { Total } \\
\text { physical }\end{array}$ & & & & 18.43 \\
\hline Mental & & & Total physical * & 4.49 \\
\hline health & & & 0.24 & \\
\hline $\begin{array}{l}\text { Overall } \\
\text { total }\end{array}$ & & & & 22.92 \\
\hline
\end{tabular}


Table A-2. Scaling of EPIC Output for 2012-2030

to Match Five WHO NCD Domains for India

GBD 2010

(trillions of 2010 USD)

EPIC

Scaled

\begin{tabular}{|c|c|c|c|c|}
\hline $\begin{array}{c}\text { WHO } \\
\text { Disease }\end{array}$ & EPIC Disease & $\begin{array}{c}\text { EPIC } \\
\text { Raw } \\
\text { Output }\end{array}$ & $\begin{array}{c}\text { Disease Scaling } \\
\text { Factor }\end{array}$ & $\begin{array}{c}\text { Scaled } \\
\text { Raw } \\
\text { Output }\end{array}$ \\
\hline Diabetes & Diabetes & 0.15 & Diabetes/1.00 & 0.15 \\
\hline $\begin{array}{l}\text { Heart } \\
\text { disease }\end{array}$ & & & $(\mathrm{IHD}+\mathrm{CBD}) / 0.77$ & 2.22 \\
\hline
\end{tabular}

Ischemic Heart $\quad 1.21$

Disease

Cerebrovascular $\quad 0.49$

Disease

\begin{tabular}{|c|c|c|c|c|}
\hline $\begin{array}{c}\text { Respiratory } \\
\text { disease }\end{array}$ & COPD & 0.71 & COPD $/ 0.70$ & 1.01 \\
\hline \multirow[t]{2}{*}{ Cancer } & & & $\begin{array}{c}\text { Breast } \\
\text { cancer/0.08 }\end{array}$ & 0.25 \\
\hline & Breast cancer & 0.02 & & \\
\hline $\begin{array}{c}\text { Total } \\
\text { physical }\end{array}$ & & & & 3.62 \\
\hline Mental & & & Total physical * & 1.15 \\
\hline health & & & 0.32 & \\
\hline $\begin{array}{c}\text { Overall } \\
\text { total }\end{array}$ & & & & 4.77 \\
\hline
\end{tabular}

